\title{
Author Correction: Biomarkers for closed-loop deep brain stimulation in Parkinson disease and beyond
}

Walid Bouthour (D), Pierre Mégevand (D), John Donoghue, Christian Lüscher, Niels Birbaumer and Paul Krack

Nature Reviews Neurology (2019) https://doi.org/10.1038/s41582-019-0166-4

Published online 1 April 2019

In the originally published article, one of the affiliations for Paul Krack was omitted - these should have included Movement Disorders Center, Department of Neurology, University Hospital (Inselspital) and University of Bern, Bern, Switzerland. This error has been corrected in the HTML and PDF versions of the manuscript.

https://doi.org/10.1038/s41582-019-0189-x I Published online 16 April 2019 